\title{
Evaluation of right ventriculoarterial coupling in pulmonary hypertension: a magnetic resonance study
}

\author{
Javier Sanz ${ }^{*}$ Ana Garcia-Alvarez Msc, Leticia Fernandez-Friera, Ajith Nair, Jesus G Mirelis, Simonette Sawit, \\ Sean Pinney, Valentin Fuster
}

From 2011 SCMR/Euro CMR Joint Scientific Sessions

Nice, France. 3-6 February 2011

\section{Introduction}

Inadequate right ventriculo-arterial coupling is an important determinant of heart failure in pulmonary hypertension, in turn the main determinant of outcome in this disease. Coupling can be quantified as the ratio of pulmonary artery effective elastance $\left(E_{a}\right.$, an index of arterial load) to right ventricular maximal end-systolic elastance $\left(E_{\max }\right.$, an index of contractility).

\section{Objective}

To quantify right ventriculo-arterial coupling in pulmonary hypertension combining standard right heart catheterization and cardiac magnetic resonance (CMR), and to noninvasively estimate it with CMR alone.

\section{Methods}

We included 139 patients undergoing CMR and right heart catheterization within 2 days ( $\mathrm{n}=151$ test pairs) for the evaluation of known or suspected pulmonary hypertension. Right ventricular end-systolic volume index (ESVI) and stroke volume index (SVI) were obtained, respectively, from cardiac cine images and phasecontrast of the pulmonary artery after adjusting for body surface area. Right heart catheterization provided mean pulmonary artery pressure (mPAP) as a surrogate of right ventricular end-systolic pressure, pulmonary capillary wedge pressure (PCWP), and pulmonary vascular resistance index (PVRI). $\mathrm{E}_{\mathrm{a}}$ was calculated as (mPAPPCWP)/SVI; and $E_{\max }$ as PAP/ESVI.

\section{Results}

$E_{a}$ increased linearly with advancing severity (as determined by PVRI quartiles; Figure, 1A), whereas $E_{\max }$ increased initially but tended to decrease subsequently (Figure, 1B). Thus, the ratio $E_{a} / E_{\max }$ was maintained in earlier stages but increased markedly (indicating
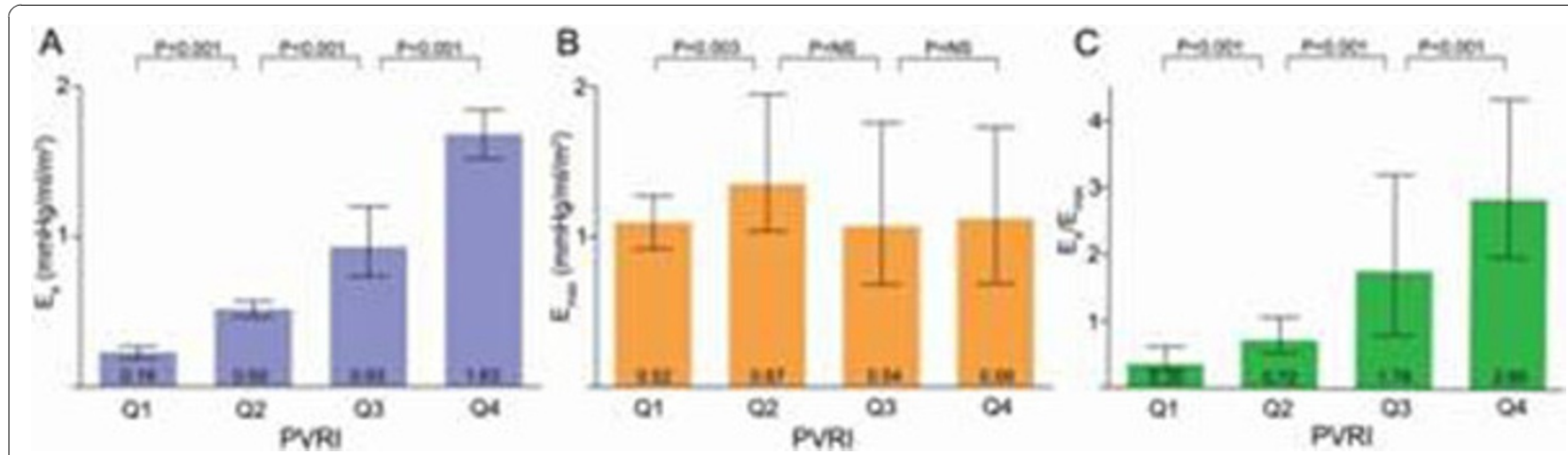

Figure $1 E_{a}, E_{\max }$ and $E_{a} / E_{\max }$ according to pulmonary hypertension severity.

Mount Sinai School of Medicine, New York, NY, USA

(c) 2011 Sanz et al; licensee BioMed Central Ltd. This is an open access article distributed under the terms of the Creative Commons 
uncoupling) with more severe pulmonary hypertension (Figure, 1C). According to underlying etiologies and after adjustment for age, gender and PVRI, there were no significant differences amongst World Health Organization groups in terms of $E_{a} / E_{\max }$. $E_{\max }$ was independently associated with right atrial pressure after adjustment for PVRI $(\beta=-2.81, \mathrm{p}<0.05)$. $\mathrm{E}_{\mathrm{a}} / \mathrm{E}_{\max }$ approximated noninvasively with CMR as ESVI/SVI equaled $0.75,1.17,2.28$, and 3.51 , for PVRI quartile groups (Q1 to $\mathrm{Q} 4)$ respectively, showing excellent correlation with $\mathrm{E}_{\mathrm{a}} / \mathrm{E}_{\max }$ derived from invasive measurements $(\mathrm{r}=0.93$, $\mathrm{p}<0.001)$ and progressing similarly with disease severity $(\mathrm{p}<0.001)$.

\section{Conclusions}

Right ventriculo-arterial coupling in pulmonary hypertension can be studied combining standard right heart catheterization and CMR indices. In addition, it can be approximated with CMR alone in a completely noninvasive fashion. Arterial load increases with disease severity whereas contractility cannot progress in parallel, leading to severe uncoupling.

Published: 2 February 2011

doi:10.1186/1532-429X-13-S1-073

Cite this article as: Sanz et al:: Evaluation of right ventriculoarterial coupling in pulmonary hypertension: a magnetic resonance study. Journal of Cardiovascular Magnetic Resonance 2011 13(Suppl 1):073.
Submit your next manuscript to BioMed Central and take full advantage of:

- Convenient online submission

- Thorough peer review

- No space constraints or color figure charges

- Immediate publication on acceptance

- Inclusion in PubMed, CAS, Scopus and Google Scholar

- Research which is freely available for redistribution

Submit your manuscript at www.biomedcentral.com/submit 